\title{
A Somogyszob, Hajmás és Kálmáncsa közötti térség kisemlős faunája, gyöngybagoly Tyto alba (Scopoli, 1769) köpetek vizsgálata alapján
}

\author{
PURGER J. JENŐ
}

PURGER, J. J.: Small mammal fauna of the region between Somogyszob, Hajmás and Kálmáncsa based on barn owl Tyto alba (Scopoli, 1769) pellet analysis

Abstract: In county Somogy, from 31 localities 2429 barn owl pellets were collected, containing 8376 prey remnants. Mammals comprised $98.3 \%$, whereas birds, amphibians, diplopods and insects made up $1.7 \%$. From remainders of mammals $47.87 \%$ were insectivores (Soricidae $47.85 \%$, Talpidac $0.02 \%$ ), $0.05 \%$ bats (Vespertilionidae), $52.07 \%$ rodents (Arvicolidae $28.50 \%$, Muridac $23.25 \%$, Gliridac $0.32 \%$ ) and $0.01 \%$ carnivores (Mustelidae).

\section{Bevezetés}

Somogy megyében az emlőstani kutatások zöme természetvédelmi szempontból jelentős, többnyire védett területeken folyt (LANSZKI \& PURGER 2001). Az eddig megjelent adatok alapján a megyében élő emlősfajok elterjedéséről, gyakoriságáról, mennyiségi viszonyairól nem alkothattunk teljes képet. A faunisztikai felmérések egy része közvetett módszerekkel történt (pl. ragadozómadarak és baglyok köpeteinek vizsgálata), elsősorban egyes madárfajok táplálkozásbiológiájának megismerése céljából (LANSZKI \& PuRger 2001). Eltekintve a munkák célkitűzéseitől, a korábbi (lásd: KaLIVODA 1994, 1999, LANSZKı \& PURGER 2001 munkáiban) és a jelenlegi (pl. LANSZKı 1999) közvetett módszerekkel végzett kutatások eredményei számos jelentős faunisztikai adattal gazdagították a megye emlöstani ismereteit.

Somogy megye kisemlős faunájának felmérése gyöngybagoly köptek vizsgálata alapján a kilencvenes években újabb lendületet vett, de ezek a vizsgálatok is elsősorban védett területeken ill. azok közvetlen közelében folytak (PURGER 1996, 1997, 1998). A faunisztikai (biotikai) adatok kompatibilitásának megteremtése érdekében (DÉVAI et al. 1997), a kisemlős fauna felmérések már a 10x10 km-es UTM rendszerü hálótérképek (Miskolczı et al. 1997) alapján, az egyes mezőknek, ill. négyzeteknek megfelelő területeken folytak.

A Somogyszob, Hajmás és Kálmáncsa települések által határolt területen előforduló kisemlősökről keveset tudunk. A megjelent töredékes adatok alapján (BITTERA 1914, GreschiK 1910, 1924, Sey 1965, Schmidt 1974a, 1974b, 1974c, 1974d, 1976, Kalotás 1989) az említett térségben 5 lelőhelyről (Lad, Lábod, Nagyatád, valamint Vörösdom és Ropoly a Zselicben), 13 emlősfaj előfordulásáról van tudomásunk.

Munkánk elsődleges célja a gyöngybaglyok tartózkodási helyeinek felkutatása és köpeteinek begyüjtése volt a Somogyszob, Hajmás és Kálmáncsa települések által határolt területen. Az emlösfauna felmérését közvetett módon, a begyüjtött köpetek tartalmának vizsgálata alapján terveztük elvégezni, hangsúlyt fektetve a védett fajokra, és a fajok között fennálló mennyiségi viszonyokra. 


\section{Anyag és módszerek}

A kisemlős fauna felméréséhez gyöngybagoly köpetek begyűjtésének és vizsgálatának módszerét alkalmaztuk (SCHMIDT 1967, MiKUSKA et al. 1979). A módszer lényege, hogy a baglyok költő és pihenőhelyein rendszerint nagymennyiségű köpet gyűjthető. A köpetekben, épségben megmaradt koponyák, állkapcsok, illetve fogak alapján az egyes emlősfajok jól elkülöníthetők egymástól. A kapott eredmények pedig visszatükrözik a környék kisemlős faunját (SCHMIDT 1967).

A köpetek begyüjtését a 10x10 km-es UTM rendszerű hálótérkép tíz négyzetének (ill. mezőjének) megfelelő területen (1. ábra), 31 lelőhelyen végeztük 1993 és 2000 között (1. táblázat). Mivel egyes lelőhelyeken többször is gyűjtöttünk, így a 31 lelőhelyről öszszesen 40 mintát ( 2429 köpetet) dolgoztunk fel (1. táblázat).

A vizsgált terület bejárását, valamint a köpetek gyüjtését Bécsy László (BL), Fenyősi László (FL), Horváth Zoltán (HZ), Mezei Ervin (ME), Nagy Tibor (NT), Pintér András (PA), Purger Jenő (PJ), Rozner György (RGY), Stix József (SJ) és a Gyöngybagolyvédelmi Alapítvány (GYA) munkatársai végezték (1. táblázat).

A köpetek túlnyomó részének korát nem lehetett biztosan meghatározni. Csak az egész köpeteket gyüjtöttük be és dolgoztuk fel. Szétbontásukat száraz technikával végeztük (SCHMIDT 1967, MiKuSKA et al. 1979). A kisemlősök meghatározása csonttani bélyegek alapján történt (ÁCS 1985, KRYŠTUFEK 1985, 1991, MÄrZ 1972, NiETHAMMER \& KRAPP 1978, 1982, 1990, SCHMIDT 1967, UJHELYI 1989, ZÖRÉNYI 1990, YALDEN 1977, YALDEN \& MORRIS 1990). A Sylvaemus szubgénuszba tartozó fajok meghatározásánál TVRTKOVIĆ (1979) módszerét követtük, és a sérülések és hiányosságok miatt meghatározhatatlan példányok, mint Apodemus sp. szerepelnek a táblázatokban (2a., 2b., 2c., 2d., 3. táblázat). A Neomys génuszba tartozó két faj, a közönséges vízicickány (Neomys fodiens) és a Miller-vízicickány (Neomys anomalus) meghatártozását TVRTKOVIĆ et al.

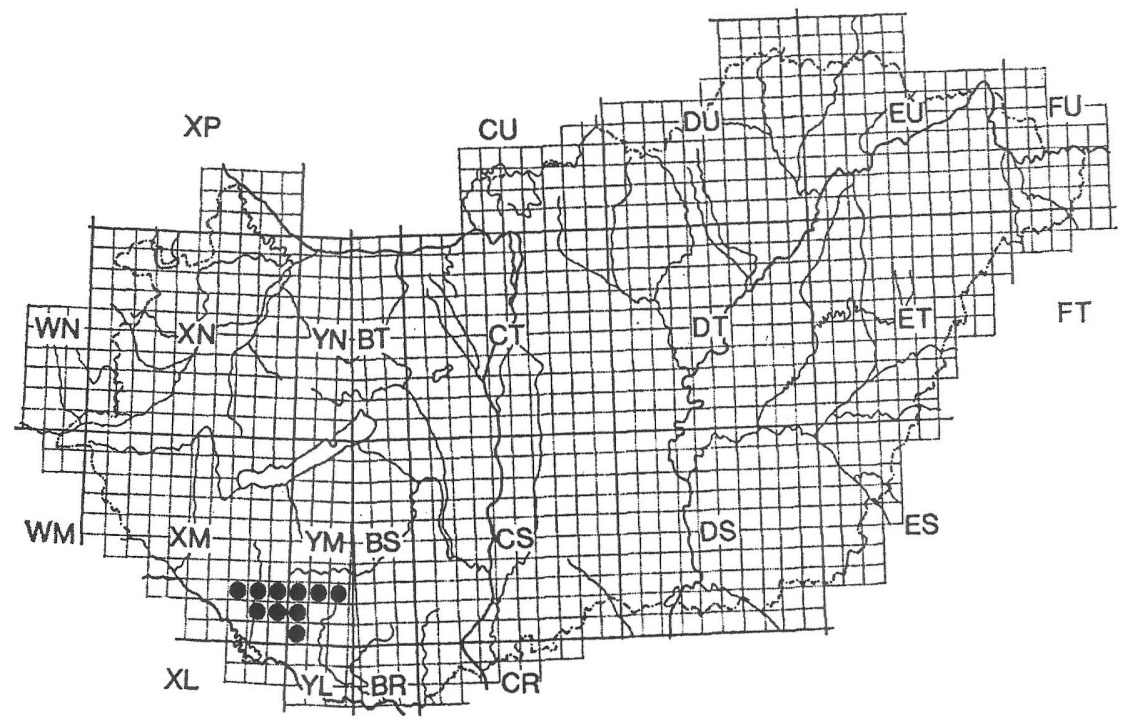

1 ábra: A vizsgált terület elhelyezkedése Magyarország UTM rendszerú hálótérképén Figure 1: Situation of the investigated area on the UTM grid map of Hungary 
1. táblázat: A különbözố lelőhelyeken gyưjtött köpetek és zsákmányállatok száma Table 1: Number of pellets and their prey contents, collected in different localities

\begin{tabular}{|c|c|c|c|c|c|c|}
\hline \multirow{2}{*}{ No. } & Lelőhely & \multirow{2}{*}{ UTM } & \multirow{2}{*}{$\begin{array}{l}\text { Dátum } \\
\text { Date }\end{array}$} & \multirow{2}{*}{\begin{tabular}{|c|} 
Gyújtök \\
Collectors \\
\end{tabular}} & \multirow{2}{*}{\begin{tabular}{|l|} 
Köpet \\
Pellet \\
\end{tabular}} & \multirow{2}{*}{$\begin{array}{c}\text { Zsákmány } \\
\text { Prey }\end{array}$} \\
\hline & Locality & & & & & \\
\hline 01. & Somogyszob (ref. temp.) & XM72 & 1996.09 .06 & $\mathrm{FL}, \mathrm{PJ}$ & 10 & 21 \\
\hline 02. & Somogyszob (istálló) & XM 72 & 2000.09 .29 & FL, PJ & 28 & 121 \\
\hline 03. & Bolhás (kastély) & XM 72 & 1996.09 .06 & FL, PJ & 47 & 173 \\
\hline 04. & Bolhás (istálló) & XM72 & 1996.09 .06 & FL, PJ & 13 & 38 \\
\hline 05. & Bolhás (ref. temp.) & XM72 & 2000.09 .29 & $\mathrm{FL}, \mathrm{PJ}$ & 47 & 144 \\
\hline 06. & Nagy barátip uszta (magtár) & $\mathrm{XM} 72$ & 1996.09 .06 & FL, PJ & 10 & 41 \\
\hline 07. & Ötvöskónyi (ref. temp.) & $\mathrm{XM} 82$ & 1997.08 .08 & FL, PJ & 17 & 55 \\
\hline 08. & Szabás (ref. temp.) & XM82 & 1997.08 .08 & $\mathrm{FL}, \mathrm{PJ}$ & 61 & 139 \\
\hline 09. & Szabás (kastély) & XM82 & 1997.08 .08 & FL, PJ & 94 & 299 \\
\hline 10. & Nagykorpád (ref. temp.) & XM82 & 1997.08 .08 & FL, PJ & 25 & 84 \\
\hline 11. & Erzsébetpuszta (lakóház) & $\mathrm{XM} 82$ & 2000.09 .29 & FL, PJ & 112 & 340 \\
\hline 12. & Lábod (istálló) & XM82 & 1993.11 .24 & NT, PJ & 16 & 106 \\
\hline 13. & Lábod (ref. temp.) & XM81 & 1996.09 .06 & FL, PJ & 70 & 221 \\
\hline $14 a$. & Riny aszentkirály (ref. temp.) & XM81 & 1996.09 .06 & FL, PJ & 169 & 678 \\
\hline $14 \mathrm{~b}$. & Riny aszentkirály (ref. temp.) & XM81 & 1999.07 .16 & GYA & 40 & 125 \\
\hline $15 \mathrm{a}$. & Görgeteg (lakóház) & XM81 & 1994.05 .08 & $\mathrm{BL}$ & 19 & 65 \\
\hline $15 \mathrm{~b}$. & Görgeteg (lakóház) & XM81 & 1996.09 .06 & FL, PJ & 14 & 70 \\
\hline 16. & Mike (burgony atároló) & XM92 & 2000.09 .29 & FL, PJ & 85 & 339 \\
\hline $17 \mathrm{a}$. & Homokszentgyörgy (ref. temp) & XM91 & 1997.07.13 & $\mathrm{HZ}$ & 22 & 67 \\
\hline $17 \mathrm{~b}$. & Homokszentgy örgy (ref. temp) & XM91 & 1997.09 .02 & $\mathrm{HZ}$ & 24 & 63 \\
\hline $17 \mathrm{c}$. & Homokszentgy örgy (ref. temp) & XM91 & 2000.09 .22 & PJ, SJ & 58 & 243 \\
\hline 18. & Rinyakovácsi (ref. temp.) & YM02 & 1997.08 .12 & $\mathrm{HZ}$ & 18 & 74 \\
\hline 19. & Kadarkút, Kenézpuszta (istálló) & YM02 & 2000.10 .18 & PJ, RGY & 44 & 125 \\
\hline 20. & Hencse (magtár) & YM01 & 1997.08 .08 & FL, PJ & 9 & 40 \\
\hline 21. & Visnye (ref. temp.) & YM01 & 2000.09 .22 & $\mathrm{PJ}, \mathrm{SJ}$ & 41 & 115 \\
\hline 22. & Gyöngyöspuszta (kastély) & YM01 & 2000.09 .22 & $\mathrm{PJ}, \mathrm{SJ}$ & 16 & 48 \\
\hline 23. & Tiltványpuszta (istálló) & YM01 & 2000.09 .22 & $\mathrm{PJ}, \mathrm{SJ}$ & 179 & 650 \\
\hline 24. & Lad (ref. temp.) & YM01 & 2000.09 .22 & $\mathrm{PJ}, \mathrm{SJ}$ & 9 & 46 \\
\hline 25. & Patosfa (magár) & YM01 & 2000.09 .22 & PJ, SJ & 25 & 90 \\
\hline 26. & Patosfa (lakóház) & YM01 & 2000.09 .22 & $\mathrm{PJ}, \mathrm{SI}$ & 164 & 394 \\
\hline $27 \mathrm{a}$. & Lajosháza (istálló) & YM00 & 1996.06.17 & FL, PJ & 369 & 1314 \\
\hline $27 \mathrm{~b}$. & Lajosháza (istálló) & YM00 & 1997.08 .11 & $\mathrm{ME}$ & 19 & 76 \\
\hline $27 \mathrm{c}$. & Lajosháza (istálló) & YM00 & 2000.09 .22 & $\mathrm{PJ}, \mathrm{SJ}$ & 34 & 115 \\
\hline $28 \mathrm{a}$. & Kálmáncsa (ref. temp.) & YM00 & 1996.06 .17 & FL, PJ & 48 & 180 \\
\hline $28 b$. & Kálmáncsa (ref. temp.) & YM00 & 2000.09 .22 & $\mathrm{PJ}, \mathrm{SJ}$ & 17 & 32 \\
\hline 29. & Böszénfa (major) & YM12 & 2000.10 .18 & PJ, RGY & 189 & 785 \\
\hline $30 \mathrm{a}$. & Hajmás (kat. temp.) & YM22 & 1995.09 .21 & PA & 25 & 96 \\
\hline $30 \mathrm{~b}$. & Hajmás (kat. temp.) & YM22 & 2000.10 .18 & PJ, RGY & 132 & 505 \\
\hline $31 \mathrm{a}$. & Gálosfa (kat, temp.) & YM22 & 1995.09 .21 & PA & 49 & 124 \\
\hline $31 \mathrm{~b}$. & Gálosfa (kat. temp.) & YM22 & 2000.10 .18 & PJ, RGY & 61 & 135 \\
\hline \multicolumn{5}{|c|}{ Összesen - Total } & 2429 & 8376 \\
\hline
\end{tabular}


(1980) által leírt módon végeztük. A házi egér (Mus musculus) és güzü egér (Mus spicilegus) elkülönítésénél MACHOLÁN (1996) határozókulcsát használtuk. A Mus és Rattus génuszba tartozó, nehezen határozható vagy sérült példányok, mint Mus $\mathrm{sp}$. és Rattus $\mathrm{sp}$. kerültek a fajlistákra (2a., 2b., 2c., 2d., 3. táblázat). Az emlősfajok tudományos- és magyar neveit MrTCHELL-JoNES et al. (1999) munkája alapján használtuk.

2a. táblázat: A köpetmintákból (1-10) előkerült zsákmányállatok száma Table 2a: Number of prey specimens in pellets of barn owl in samples (1-10)

\begin{tabular}{|l|c|c|c|c|c|c|c|c|c|c|}
\hline Zsákmány - Prey & $\mathbf{0 1}$ & $\mathbf{0 2}$ & $\mathbf{0 3}$ & $\mathbf{0 4}$ & $\mathbf{0 5}$ & $\mathbf{0 6}$ & $\mathbf{0 7}$ & $\mathbf{0 8}$ & $\mathbf{0 9}$ & $\mathbf{1 0}$ \\
\hline Sorex araneus & 1 & 44 & 21 & 3 & 25 & 4 & 10 & 20 & 39 & 4 \\
\hline Sorex minutus & 1 & 15 & 10 & 1 & 5 & 11 & 2 & 2 & 20 & 1 \\
\hline Neomys anomalus & 2 & 4 & 1 & 1 & 6 & 1 & 2 & 9 & 3 & - \\
\hline Neomys fodiens & 1 & 1 & - & - & 1 & - & - & - & - & - \\
\hline Crocidura leucodon & - & 1 & 22 & 1 & 3 & 3 & 2 & 2 & 11 & 5 \\
\hline Crocidura suaveolens & - & 8 & 37 & 7 & 17 & 5 & 5 & 11 & 30 & 12 \\
\hline Talpa europaea & 1 & - & - & - & - & - & - & - & 1 & - \\
\hline Eptesicus serotinus & - & - & - & - & 1 & - & - & - & - & - \\
\hline Plecotus austriacus & - & - & - & - & 1 & - & - & - & - & - \\
\hline Clethrionomys glareolus & - & 6 & 9 & - & 8 & 1 & 1 & 3 & 5 & 5 \\
\hline Arvicola terrestris & - & - & - & - & - & - & - & - & 3 & 1 \\
\hline Microtus agrestis & - & 4 & 1 & - & 5 & 1 & 2 & 3 & 5 & 2 \\
\hline Microtus arvalis & 6 & 16 & 23 & 12 & 24 & - & 15 & 54 & 116 & 37 \\
\hline Microtus subterraneus & - & 1 & 2 & 1 & 2 & - & 4 & - & 2 & 6 \\
\hline Micromys minutus & 1 & 4 & 12 & 12 & 5 & 3 & 2 & - & 7 & - \\
\hline Apodemus agrarius & 4 & 11 & 16 & - & 18 & 8 & 7 & 13 & 10 & 6 \\
\hline Apodemus flavicollis & - & - & 1 & - & 2 & - & - & 1 & 2 & - \\
\hline Apodemus sylvaticus & 2 & 2 & 6 & - & 5 & 2 & 1 & 4 & 5 & - \\
\hline Apodemus sp. & - & - & 1 & - & 1 & 2 & 1 & 3 & 2 & 2 \\
\hline Rattus norvegicus & - & - & 1 & - & - & - & - & - & 5 & - \\
\hline Rattus sp. & - & - & 1 & - & - & - & - & 1 & 3 & - \\
\hline Mus musculus & 2 & 2 & - & - & 5 & - & 1 & 5 & 5 & 1 \\
\hline Mus spicilegus & - & - & 1 & - & 1 & - & - & 3 & 10 & - \\
\hline Mus sp. & - & 2 & - & - & 1 & - & - & 2 & 2 & 1 \\
\hline Muscardinus avellanarius & - & - & - & - & 1 & - & - & - & - & 1 \\
\hline Aves (indet.) & - & - & 7 & - & 5 & - & - & 3 & 13 & - \\
\hline Amphibia (Rana sp.) & - & - & - & - & 1 & - & - & - & - & - \\
\hline Insecta (Coleoptera) & - & - & - & - & 1 & - & - & - & - & - \\
\hline Összesen - Total & 21 & 121 & 173 & 38 & 144 & 41 & 55 & 139 & 299 & 84 \\
\hline
\end{tabular}




\section{Eredmények}

Somogy megyében a Somogyszob, Hajmás és Kálmáncsa települések által határolt térségből (1. ábra) 31 lelőhelyről (1. táblázat) kerültek elő gyöngybagoly köpetek. A lelőhelyek helyszínei 14 esetben (45\%) egyházi épületek (templomok tornyai és padlásai), 17 esetben $(55 \%)$ pedig lakó, ill. gazdasági épületek padlásain voltak.

2b. táblázat: A köpetmintákból (11-17b) előkerült zsákmányállatok száma Table 2b: Number of prey specimens in pellets of barn owl in samples (11-17b)

\begin{tabular}{|c|c|c|c|c|c|c|c|c|c|c|}
\hline Zsákmány - Prey & 11. & 12. & 13. & $14 a$. & $14 \mathrm{~b}$. & $15 a$. & $15 \mathrm{~b}$. & 16. & 17a. & $17 \mathrm{~b}$. \\
\hline Sorex araneus & 51 & 21 & 9 & 85 & 5 & 5 & 24 & 83 & 31 & 16 \\
\hline Sorex minutus & 13 & 13 & 3 & 23 & 2 & 1 & 11 & 19 & 1 & 4 \\
\hline Neomys anomalus & 4 & - & 18 & 19 & 2 & 1 & 2 & 37 & 4 & 2 \\
\hline Neomys fodiens & - & - & - & 2 & - & - & 1 & 2 & - & - \\
\hline Crocidura leucodon & 12 & 10 & 8 & 77 & 3 & 24 & 1 & 19 & - & - \\
\hline Crocidura suaveolens & 41 & 29 & 18 & 117 & 15 & 4 & 2 & 44 & 2 & 1 \\
\hline Eptesicus serotinus & - & - & 1 & - & - & - & - & - & - & - \\
\hline Clethrionomys glareolus & 4 & - & 8 & 4 & 1 & 1 & 3 & 1 & 1 & - \\
\hline Arvicola terrestris & 3 & - & - & 1 & - & - & - & - & 1 & - \\
\hline Microtus agrestis & 2 & 3 & 4 & 19 & 3 & 2 & 6 & 6 & 1 & 5 \\
\hline Microtus arvalis & 46 & 19 & 71 & 214 & 38 & 18 & 6 & 47 & 15 & 18 \\
\hline Microtus subterraneus & 13 & - & 7 & 9 & 2 & - & 2 & 7 & - & 1 \\
\hline Micromys minutus & 11 & 2 & 11 & 14 & 9 & - & 1 & 12 & - & - \\
\hline Apodemus agrarius & 81 & 4 & 28 & 55 & 12 & 5 & 7 & 41 & 1 & 10 \\
\hline Apodemus flavicollis & 8 & - & 2 & 3 & 2 & - & - & 2 & - & - \\
\hline Apodemus sylvaticus & 8 & 3 & 9 & 9 & 11 & 1 & 2 & 9 & 3 & 2 \\
\hline Apodemus sp. & 11 & - & 4 & 4 & 3 & 2 & 1 & 1 & 2 & 2 \\
\hline Rattus norvegicus & 9 & - & - & - & - & - & - & - & - & - \\
\hline Rattus sp. & 3 & - & 1 & - & - & - & - & - & - & - \\
\hline Mus musculus & 7 & - & 2 & 2 & 16 & - & - & 2 & 2 & - \\
\hline Mus spicilegus & 4 & 2 & 10 & 10 & - & 1 & 1 & 2 & 1 & - \\
\hline Mussp. & 3 & - & 3 & 3 & - & - & - & - & - & - \\
\hline Muscardinus avellanarius & - & - & 1 & 1 & - & - & - & - & - & - \\
\hline Aves (indet.) & - & - & 2 & 6 & 1 & - & - & 4 & 2 & 1 \\
\hline Amphibia (Pelobates fuscus) & 2 & - & - & 1 & - & - & - & 1 & - & 1 \\
\hline Amphibia (Rana sp.) & - & - & 1 & - & - & - & - & - & - & - \\
\hline Insecta (Coleoptera) & 4 & - & - & - & - & - & - & - & - & - \\
\hline Összesen - Total & 340 & 106 & 221 & 678 & 125 & 65 & 70 & 339 & 67 & 63 \\
\hline
\end{tabular}


Összesen 2429 köpetet gyüjtöttünk be, melyekből 8376 zsákmányállat maradványai kerültek elö (1. táblázat). Egy köpetben átlagosan 3.4 zsákmányállat volt.

A szétbontott köpetekben 25 kisemlősfaj 8232 egyedének maradványa volt (3. táblázat), tehát a köpetekben a kisemlösök domináltak (98.3\%). A madár-, kétéltü-, ikerszelvényes- és rovarmaradványok a zsákmányállatok mindössze 1.7\%-át tették ki (2a., 2b., 2c., 2d. táblázat).

Az emlősök 47.87\%-a a rovarevők (Insectivora), 0.05\%-a a denevérek (Chiroptera), $52.07 \%$-a rágcsálók (Rodentia), 0.01\%-a pedig a ragadozók (Carnivora) rendjébe sorolható. A gyöngybaglyok emlős táplálékának $47.85 \%$-át a cickányfélék (Soricidae),

2c. táblázat: A köpetmintákból (17c-26) elökerült zsákmányállatok száma Table 2c: Number of prey specimens in pellets of barn owl in samples $(17 \mathrm{c}-26)$

\begin{tabular}{|l|c|c|c|c|c|c|c|c|c|c|}
\hline Zsákmány - Prey & $\mathbf{1 7 c}$ & $\mathbf{1 8}$ & $\mathbf{1 9}$ & $\mathbf{2 0}$ & $\mathbf{2 1}$ & $\mathbf{2 2}$ & $\mathbf{2 3}$ & $\mathbf{2 4}$ & $\mathbf{2 5}$ & $\mathbf{2 6}$ \\
\hline Sorex araneus & 36 & 25 & 18 & 13 & 5 & 15 & 127 & 24 & 18 & 55 \\
\hline Sorex minufus & 7 & 4 & 1 & 5 & 2 & 2 & 33 & 8 & 7 & 7 \\
\hline Neomys anomalus & - & - & 2 & 4 & - & 5 & 21 & 3 & 9 & 55 \\
\hline Neomis fodiens & - & - & - & - & - & - & 2 & 1 & 2 & 1 \\
\hline Crocidura leucodon & 32 & 5 & 6 & 6 & 6 & 2 & 56 & 1 & - & 10 \\
\hline Crocidura suaveolens & 38 & 5 & 13 & 2 & 20 & 4 & 51 & 3 & 5 & 26 \\
\hline Clethrionomys glareolus & - & 1 & 8 & 1 & - & - & 5 & - & 4 & 9 \\
\hline Arvicola terrestris & - & - & - & - & - & - & - & - & - & 1 \\
\hline Microtus agrestis & 3 & 1 & 2 & 1 & 3 & 6 & 8 & - & 3 & 32 \\
\hline Microtus arvalis & 38 & 21 & 32 & 1 & 20 & 5 & 142 & 4 & 6 & 67 \\
\hline Microtus subterraneus & - & 1 & 1 & - & 1 & 1 & 18 & 1 & 3 & 9 \\
\hline Micromys minutus & 5 & - & 1 & 1 & 1 & 2 & 10 & - & 1 & 6 \\
\hline Apodemus agrarius & 9 & 3 & 21 & 3 & 13 & 1 & 48 & 1 & 21 & 40 \\
\hline Apodemus flavicollis & 4 & 1 & 4 & 1 & 16 & 2 & 11 & - & - & 13 \\
\hline Apodemus sylvaticus & 13 & 3 & 2 & - & 2 & - & 16 & - & 5 & 12 \\
\hline Apodemus sp. & 9 & 1 & 2 & 1 & 12 & - & 20 & - & - & 22 \\
\hline Rattus sp. & - & - & - & - & - & - & - & - & - & 1 \\
\hline Mus musculus & 3 & 1 & 2 & - & - & 1 & 18 & - & 2 & 7 \\
\hline Mus spicilegus & 6 & - & 3 & - & 7 & - & 40 & - & 1 & 15 \\
\hline Mus sp. & 9 & - & 2 & - & 4 & 1 & 10 & - & 1 & 4 \\
\hline Glis glis & - & - & 1 & - & - & - & - & - & - & - \\
\hline Muscardinus avellanarius & 1 & 1 & 1 & - & 2 & - & 1 & - & - & 1 \\
\hline Aves (indet.) & 1 & - & 3 & 1 & 1 & 1 & 6 & - & 2 & 1 \\
\hline Amphibia (Pelobates fuscus) & 17 & 1 & - & - & - & - & 5 & - & - & - \\
\hline Diplopoda (indet.) & - & - & - & - & - & - & 1 & - & - & - \\
\hline Insecta (Coleoptera) & 11 & - & - & - & - & - & 1 & - & - & - \\
\hline Összesen - Total & 243 & $\mathbf{7 4}$ & $\mathbf{1 2 5}$ & $\mathbf{4 0}$ & 115 & $\mathbf{4 8}$ & $\mathbf{6 5 0}$ & 46 & $\mathbf{9 0}$ & $\mathbf{3 9 4}$ \\
\hline
\end{tabular}


$0.02 \%$-át a vakondfélék (Talpidae), 0.05\%-át a simaorrú denevérek (Vespertilionidae), 28.50\%-át a pocokfélék (Arvicolidae), 23.25\%-át az egérfélék (Muridae), 0.32\%-át a pelefélék (Gliridae), 0.01\%-át pedig a menyétfélék (Mustelidae) családjába tartozó fajok egyedei alkották (2a., 2b., 2c., 2d., 3. táblázat).

2d. táblázat: A köpetmintákból (27a - 31b) előkerült zsákmányállatok száma Table 2d: Number of prey specimens in pellets of barn owl in samples (27a-31b)

\begin{tabular}{|c|c|c|c|c|c|c|c|c|c|c|}
\hline Zsákmány - Prey & 27 a. & $27 \mathrm{~b}$. & $27 \mathrm{c}$. & $28 \mathrm{a}$. & $28 \mathrm{~b}$. & 29. & 30a. & $30 \mathrm{~b}$. & $31 \mathrm{a}$. & $31 \mathrm{~b}$ \\
\hline Sorex araneus & 108 & 32 & 7 & 74 & 1 & 155 & 1 & 71 & 2 & 12 \\
\hline Sorex minutus & 53 & 9 & 5 & 17 & 1 & 43 & 8 & 51 & 4 & 3 \\
\hline Neomys anomalus & 28 & 7 & 10 & 3 & - & 38 & - & 20 & 1 & 4 \\
\hline Neomys fodiens & 3 & - & 1 & 1 & - & - & - & - & - & - \\
\hline Crocidura leucodon & 173 & 6 & 3 & 5 & - & 21 & 25 & 57 & 12 & 2 \\
\hline Crocidura suaveolens & 253 & 6 & 17 & 14 & 1 & 185 & 36 & 110 & 12 & 25 \\
\hline Myotis myotis & - & - & - & - & - & - & - & 1 & - & - \\
\hline Clethrionomys glareolus & 7 & - & - & - & - & 11 & - & 5 & - & - \\
\hline Arvicola terrestris & 4 & - & - & - & - & 10 & - & 2 & - & 1 \\
\hline Microtus agrestis & 17 & 2 & 5 & 4 & 3 & 15 & - & 2 & - & 3 \\
\hline Microtus arvalis & 327 & 6 & 33 & 26 & 16 & 151 & 12 & 98 & 57 & 44 \\
\hline Microtus subterraneus & 4 & - & 2 & 4 & - & 13 & - & 4 & 1 & - \\
\hline Micromys minutus & 55 & - & 6 & 2 & 1 & 32 & - & 5 & - & 1 \\
\hline Apodemus agrarius & 110 & 2 & 11 & 4 & 3 & 39 & - & 21 & 3 & 9 \\
\hline Apodemus flavicollis & 18 & 1 & 3 & - & - & 30 & 4 & 19 & 21 & 13 \\
\hline Apodemus sylvaticus & 37 & 3 & 3 & 3 & 1 & 12 & 2 & 4 & 3 & 4 \\
\hline Apodemus sp. & 23 & - & 2 & 2 & - & 11 & 2 & 10 & 5 & 5 \\
\hline Rattus norvegicus & 2 & - & - & - & - & - & - & 2 & - & - \\
\hline Rattus sp. & 3 & - & - & 1 & - & 1 & - & - & - & - \\
\hline Mus musculus & 30 & 1 & 5 & 8 & 5 & 12 & - & 2 & - & 1 \\
\hline Mus spicilegus & 29 & - & 1 & 4 & - & 3 & - & - & 3 & 5 \\
\hline Mussp. & 20 & - & - & 1 & - & 1 & - & 1 & - & - \\
\hline Glis glis & - & - & - & - & - & 1 & - & - & - & - \\
\hline Muscardinus avellanarius & 6 & - & 1 & 1 & - & 1 & - & 3 & - & - \\
\hline Mustela nivalis & 1 & - & - & - & - & - & - & - & - & - \\
\hline Aves (indet.) & - & 1 & - & 6 & - & - & 6 & 14 & - & 2 \\
\hline Amphibia (Pelobates fuscus) & 1 & - & - & - & - & - & - & - & - & - \\
\hline Amphibia (Rana sp.) & - & - & - & - & - & - & - & 2 & - & - \\
\hline Insecta (Coleoptera) & 2 & - & - & - & - & - & - & 1 & - & - \\
\hline Insecta (Lepidoptera) & - & - & - & - & - & - & - & - & - & 1 \\
\hline Összesen - Total & 1314 & 76 & 115 & 180 & 32 & 785 & 96 & 505 & 124 & 135 \\
\hline
\end{tabular}




\section{Következtetések}

A nagymennyiségű köpet (1. táblázat) begyűjtése és feldolgozása nem volt hiábavaló, hiszen 25 emlősfaj előfordulásáról és mennyiségi viszonyairól kaptunk képet (3. táblázat). Ebből a védett fajok listáján (13/2001. (V.9.) KöM rendelete) 13 emlősfaj (7 rovarevő, 3 denevér és 3 rágcsáló) szerepel.

A területen élő gyöngybaglyok a vizsgált időszakban elsősorban cickányféléket (Soricidae) fogyasztottak (az emlőszsákmány 47.85\%-a cickányokból állt). A kimutatott 6 cickányfaj közül 5 (erdei cickány Sorex araneus, törpecickány Sorex minutus, Millervízicikány Neomys anomalus, mezei cickány Crocidura leucodon, keleti cickány Crocidura suaveolens) jelentős számban fordult elő mind a 10 vizsgált UTM négyzet területén (3. táblázat). A gyöngybaglyok táplálkozása szempontjából a keleti cickány bizonyult a második leggyakoribb zsákmánynak (az emlőszsákmány 14.95\%-át tette ki). A közönséges vízicikány (Neomys fodiens) pedig csak helyenként és kis számban fordult elő (2a., 2b., 2c., 2d., 3 táblázat).

SCHMIDT (1976) a Lábadon gyüjtött bagolyköpetekből 3 cickányfajt mutatott ki (törpecickányt, mezei cickányt és a keleti cickányt). KaLOTÁs (1989) pedig a Zselicben (Vörösdom) gyűjtött macskabagoly (Stix aluco) köpetekben talált mezei cickányt.

A közönséges vakond (Talpa europaea) életmódja miatt ritkán esik a baglyok áldozatául. A vizsgált területről eddig nem mutatták ki, de maradványai most két mintából (Somogyszob, Szabás) is elökerültek (2a., 3. táblázat).

Somogy megye denevérfaunájáról nagyon kevés, a vizsgált területről pedig egyáltalán nincs publikált adat (LANSZKI \& PURGER 2001). A köpetekből előkerült mindhárom faj (közönséges denevér Myotis myotis, közönséges késeidenevér Eptesicus serotinus, szürke hosszúfülü-denevér Plecotus austriacus) épületlakó denevér (BIHARI 1996). Valószínü, hogy az említett denevérfajok előfordulási helyei megegyeztek a gyöngybaglyok pihenő-, illetve költőhelyével, igy azok áldozatává váltak.

A cickányok után a pocokfélék (Arvicolidae) a legjelentősebb zsákmányállatai a területen élő gyöngybaglyoknak, hiszen az emlőszsákmány $28.50 \%$-át tették ki. A vizsgált területen valószínü, hogy a mezei pocok (Microuts arvalis) a leggyakoribb emlősfaj, hiszen a köpetekből e faj maradványai kerültek elő a legnagyobb számban (2a., 2b., 2c., 2d., 3. táblázat). Annak ellenére, hogy minden vizsgált UTM négyzet területén előfordult a vöröshátú erdeipocok (Clethrionomys glareolus), a csalitjáró pocok (Microtus agrestis) és a közönséges földipocok (Microtus subterraneus), a gyöngybaglyok táplálkozása szempontjából e fajok nem mondhatók jelentősnek. A vizsgált területről az emlitett négy fajt már korábban is kimutatták (BITTERA 1914, GRESCHIK 1910,1924, SCHMIDT 1974a, 1974b, 1974d, 1976, KALOTÁs 1989). A közönséges kószapocok (Arvicola terrestris) nagyobb termeténél, vagy életmódjánál fogva az előbb felsorolt fajoknál ritkábban került a baglyok zsákmányai közé. Előfordulásáról a területen eddig nem volt tudomásunk. A köpetekböl kimutatott 5 pocokfaj közül csak a csalitjáró pocok védett.

Az egérfélék részesedése (23.25\%) a gyöngybaglyok táplálékában szintén jelentősnek mondható. A vizsgált terület egészén jelentős számban fordultak elő a kisebb termetű fajok, mint a törpeegér (Micromys minutus) a pirók erdeiegér (Apodemus agrarius), a sárganyakú erdeiegér (Apodemus falvicollis), a közönséges erdeiegér (Apodemus sylvaticus), a házi egér (Mus musculus) és a güzü egér (Mus spicilegus). Az emlitett fajoknál ritkábban kerültek elő a nagyobb termetű és agressziv természetű vándorpatkány (Rattus norvegicus) maradványai (2a., 2b., 2d., 3. táblázat). A korábbi vizsgálati eredmények a közönséges erdeiegér (Lad), a törpeegér (Lábod), a pirók erdeiegér (Lábod) és a házi egér (Lábod, Vörösdomb) előfordulásáról számoltak be (GRESCHIK 1910, SCHMIDT 1976, KaLOTÁs 1989). 
A pelefélék (Gliridae) nem tartoznak a gyöngybaglyok gyakori zsákmányai közé, hiszen az emlőszsákmánynak csak $0.32 \%$-át képezték. A nagy pele (Glis glis) magyarországi elterjedéséről ismereteink hiányosak (Bakó et al. 1998), Somogy megyei előfordulásáról pedig alig van adat (LANSzKI \& PURGER 2001). A Somogyszob, Hajmás és Kálmáncsa közötti térségből eddig nem mutatták ki, ezért jentősek a Kadarkúton és Bőszénfán gyüjtött köpetekből előkerült példányok (2a. táblázat). A mogyorós pele (Muscardinus avellanarius) elterjedéséről több információnk van (BAKó et al. 1998, LANSZKI \& PURGER 2001), sőt SCHMIDT (1974c) a vizsgált területen (Lábod) is kimutatta. A mogyorós pele sem mondható gyakorinak, de egy UTM mező (XM92) kivételével szinte az egész vizsgált területen jelen van (3. táblázat). Mindkét pelefaj védett.

A ragadozó emlősfajok ritkán esnek a baglyok áldozatául, de a kis termetű eurázsiai menyét (Mustela nivalis) egy példánya mégis elökerült a Lajosházán gyüjtött köpetekből (2d. táblázat).

A Somogyszob, Hajmás és Kálmáncsa települések között elterülő térségből a pézsmapocok (Ondatra zibethicus) kivételével (SEY 1965) minden korábban ismert emlősfaj (11 faj) előfordulása megerősítést nyert. A köpetekből 14, a területre új emlősfaj számos egyede is előkerült, így eredményeink 25 kisemlős faj elterjedési és mennyiségi adataival gazdagítják Somogy megye emlösfaunájának ismeretanyagát.

3. táblázat: Az emlősfajok mennyiségi megoszlása a vizsgált UTM négyzetekben.

Table 3: Quantitative distribution of mammal species in the investigated UTM grids

\begin{tabular}{|c|c|c|c|c|c|c|c|c|c|c|}
\hline Zsák mány - Prey & XM72 & XM82 & XM81 & XM92 & XM91 & YM02 & YMO1 & YMO0 & $\mathrm{YM} 12$ & YM22 \\
\hline Sorex ar anews & 98 & 145 & 128 & 83 & 83 & 43 & 257 & 222 & 155 & 86 \\
\hline Sorex minutus & 43 & 51 & 40 & 19 & 12 & 5 & 64 & 85 & 43 & 66 \\
\hline Neomys anomahs & 15 & 18 & 42 & 37 & 7 & 2 & 97 & 48 & 38 & 25 \\
\hline Neomys fodiens & 3 & - & 3 & 2 & - & - & 6 & 5 & - & - \\
\hline Crocidura leacodon & 30 & 42 & 113 & 19 & 32 & 11 & 81 & 187 & 21 & 96 \\
\hline Crocid ura suaveolens & 74 & 128 & 156 & 44 & 41 & 18 & 111 & 291 & 185 & 183 \\
\hline Talpa europaea & 1 & 1 & - & - & $\therefore$ & - & $\therefore$ & - & - & - \\
\hline Myotis myotis & - & - & - & 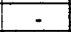 & - & - & - & - & - & 1 \\
\hline Eptesicus serotinus & 1 & - & 1 & . & - & - & - & - & - & - \\
\hline Plecotus austriacus & 1 & - & - & - & - & - & - & - & - & - \\
\hline Clethrionomys glareohus & 24 & 18 & 17 & 1 & 1 & 9 & 19 & 7 & 11 & 5 \\
\hline Arvicola terres br is & . & 7 & 1 & - & 1 & - & 1 & 4 & 10 & 3 \\
\hline Microtus agrestis & 11 & 17 & 34 & 6 & 9 & 3 & 53 & 31 & 15 & 5 \\
\hline Microtus arvalis & 81 & 287 & 347 & 47 & 71 & 53 & 245 & 408 & 151 & 211 \\
\hline Microtus subterrane us & 6 & 25 & 20 & 7 & 1 & 2 & 33 & 10 & 13 & 5 \\
\hline Micromys minutus & 37 & 22 & 35 & 12 & 5 & 1 & 21 & 64 & 32 & 6 \\
\hline Apodemus agrarios & 57 & 121 & 107 & 41 & 20 & 24 & 127 & 130 & 39 & 33 \\
\hline Apodemus flavicollis & 3 & 11 & 7 & 2 & 4 & 5 & 43 & 22 & 30 & 57 \\
\hline Apodemus sylvaticus & 17 & 21 & 32 & 9 & 18 & 5 & 35 & 47 & 12 & 13 \\
\hline Apodemus sp. & 4 & 19 & 14 & 1 & 13 & 3 & 55 & 27 & 11 & 22 \\
\hline Rathos norv egicus & 1 & 14 & - & - & - & - & - & 2 & - & 2 \\
\hline Rathis sp. & 1 & 7 & 1 & - & - & - & 1 & 4 & 1 & . \\
\hline Mus musculus & 9 & 19 & 20 & 2 & 5 & 3 & 28 & 49 & 12 & 3 \\
\hline Muss spicilegus & 2 & 19 & 22 & 2 & 7 & 3 & 63 & 34 & 3 & 8 \\
\hline Mus sp. & 3 & 8 & 6 & - & 9 & 2 & 20 & $2 !$ & 1 & 1 \\
\hline Glis glis & - & . & $\therefore$ & - & - & 1 & . & - & 1 & - \\
\hline Muscardinus avellanarias & 2 & 1 & 2 & - & 1 & 2 & 4 & 8 & 1 & 3 \\
\hline Mustela niv alis & - & $\cdot$ & - & $\therefore$ & - & $\therefore$ & $\therefore$ & 1 & - & - \\
\hline Összesen - Total & 524 & 1001 & 1148 & 334 & 340 & 195 & 1364 & 1707 & 785 & 834 \\
\hline
\end{tabular}




\section{Köszönetnyilvánítás}

Szeretném megköszönni Bécsy Lászlónak, Fenyősi Lászlónak, Horváth Zoltánnak, Mezei Ervinnek, Nagy Tibornak, Pintér Andrásnak, Rozner Györgynek, Stix Józsefnek és a Gyöngybagolyvédelmi Alapítvány munkatársainak a köpetek begyüjtésénél, Csorba Gábornak a denevérek meghatározásánál, Bihari Zoltánnak pedig az emlőstani irodalom összegyüjtésénél nyújtott segítséget. A terepkiszállásokat, és a dolgozat megírásának költségeit a Janus Pannonius Tudományegyetem Alapítványa fedezte.

\section{Irodalom}

Ács, A. 1985: A bagolyköpetvizsgálatok alapjai. A Magyar Madártani Egyesület Zalai Helyi Csoportjának kiadványa, Zalaegerszeg.

BAKÓ, B., CSORBA, G. \& BERTY, L. 1998: Distribution and ccological requirements of dormouse species occurring in Hungary. Nat. Croat. 7(1): 1-9.

Bihari, Z. 1996: Denevérhatározó és denevérvédelem. A Magyar Madártani és Természetvédelmi Egyesület (MME) Könyvtára 10. Budapest.

BITTERA, Gy. 1914: Nappali ragadozó madaraink gyomortartalom-vizsgálata. Aquila 21: 230-238.

DÉVAI, Gy., Miskolczi, M. \& TóTH, S. 1997: Egységesítési javaslat a névhasználatra és az UTM rendszerü kódolásra a biotikai adatok lelöhelyeinél. Acta. Biol. Debr. Occol. Hung. 8: 13-42.

KALIVODA, B. 1994: A magyar bagoly-táplálkozásvizsgálati irodalom bibliográfiája és cmlőstani clemzésc. Diplomadolgozat, ELTE, TTK, Budapest.

GRESCHIK, J. 1910: Hazai ragadozómadaraink gyomor- és köpcttartalom vizsgálata I. Gatyásölyv - Archibuteo lagopus (Brün.), cgerészőölyv- Butco buteo (L.), erdei fülcsbagoly- Asio otus (L.). Aquila 17:168-179.

GresCHIK, J. 1924: Gyomor és köpettartalom vizsgálatok. Adatok a hazai apró emlöscink faunájảhoz 111. Ölyvek és baglyok. Aquila 30-31: 243-263.

KALIVODA, B. 1999: A magyar bagoly-táplálkozástani irodalom annotált bibliográfiája. Crisicum 2: 221 -254.

KALOTÁs, Zs. 1989: Adatok a macskabagoly (Strix aluco) táplálkozásához. Madártani Tájćkoztató jan.-jún.: 2935.

KRYŠtufEK, B. 1985: Mali sesalci. Naša rodna zemlja 4. Prirodoslovno društvo Slovenije, Ljubljana.

KRYŠtufeK, B. 1991: Sesalci Slovenije. Prirodoslovni muzej Slovenije, Ljubljana.

LANSZKı, J. 1999: Faunisztikai vizsgálat a Balaton-Dráva ökológiai hálózatban közvetett módszerckkel. Somogyi Müszaki Szemle 23: 22-28.

LANSZKI, J. \& PurGER, J. J. 2001: Somogy megye emlős faunája (Mammalia). Natura Somogyicnsis 1: 481-494.

MACHOLÁN, M. 1996: Key to European house mice (Mus). Folia Zool. 45(3): 209-217.

MÄRZ, R. 1972: Gewöll- und Rupfungskunde. Akademie Verlag, Berlin.

Mikuska, J., TvrTKovıć, N. \& Džukıć, G. 1979: Sakupljanje i analiza gvalica ptica kao jedna od važnih metoda upoznavanja faune naših sisara. Arh. biol. nauka 29(3-4): 157-160.

MiskolCZI, M., DÉvAI, Gy., KERTÉsz, GY. \& BAJZA, Á. 1997. A magyarországi helysćgek kódjegyzéke az UTM rendszerü 10(10 km beosztású hálótérkép szerint. Acta. Biol. Debr. Oecol. Hung. 8: 43-194.

Mitchell-Jones, A. J., Amorı, G., Bogdanowicz, W., KryŠtufek, B., Reijnders, P. J. H., Spitzenberger, F., Stubbe, M., Thissen, J. B. M., Vohralík, V. \& Zima, J. 1999: Atlas of European Mammals. The Academic Press, London.

NieTHAMmer, J. \& KRAPP, F. (ed.) 1978: Handbuch der Säugetiere Europas. Band 1. Nageticre I. Akademische Verlagsgesellschaft, Wiesbaden.

Niethammer, J. \& Krapp, F. (ed.) 1982: Handbuch der Säugeticre Europas. Band 2/I. Nageticre II. Akademische Verlagsgesellschaft, Wiesbaden.

Niethammer, J. \& KrapP, F. (cd.) 1990: Handbuch der Säugeticre Europas. Band 3/I. Insektenfresser, Herrenticre. AULA - Verlag, Wiesbaden.

Purger, J. J. 1996: A Boronka-melléki Tájvédelmi Körzet kcleti határvidékénck (Somogy megye) kiscmlös faunája, gyöngybagoly, Tyto alba (Scopoli, 1769) köpetck vizsgálata alapján. Somogyi Múzcumok Közleményei 12: 299-302.

PuRger, J. J. 1997: A csokonyavisontai halastavak (Somogy megye) környékének kisemlös faunája, gyöngybagoly köpetek vizsgálata alapján. Természetvédelmi Közleményck 5-6: 105-109. 
PURGer, J. J. 1998: A Dráva mente Somogy megyei szakaszának kisemlős (Mammalia) faunája, gyöngybagoly, Tyto alba (Scopoli, 1769) köpetek vizsgálata alapján. Dunántúli Dolg. Term. tud. Sorozat. 9: 489 500.

SCHMIDT, E. 1967: Bagolyköpet vizsgálatok. Magyar Madártani Intézet. Budapest.

SCHMIDT, E. 1974a: A magyarországi mezei pocok (Microtus arvalis) állomány relatív sürüsége 1969-71-ben bagolyköpetek vizsgálata alapján. Aquila 78-79: 189-196.

SCMIDT, E. 1974b: Über die Verbreitung und Wohndichte der Kleinwühlmaus (Pitymys subterraneus (De Sclys-Longchamps) in Ungarn. Vertebrata Hungarica 15: 45-52.

SCHMIDT, E. 1974c: Pele elöfordulási adatok bagolyköpctekböl. Állattani Közleményck 61(1-4): 117-118.

SchmiDT, E. 1974d: Die Verbreitung der Erdmaus, Microtus agrestis (Linné, 1761), in Ungarn. Säugetierk. Mitt. 22: 61-64.

SCHMIDT, E. 1976: Klcinsäugerfaunistische Daten aus Eulengewöllen in Ungarn. Aquila 82: 119-144.

SEY, O. 1965: A pézsmapocok (Ondatra zibethica) (L., 1776) magyarországi belső élősködő férgei I. Vertebrata Hungarica 7(1-2): 153-175.

UjHELY, P. 1989: A magyarországi vadonélö emlösállatok hatảrozója (Küllemi és csonttani bélyegek alapján). A Magyar Madártani és Természetvédelmi Egyesület (MME) Könyvtára 1. Budapest.

TVRTKovı́́, N. 1979: Razlikovanje i određivanje morfološki sličnih vrsta podroda Sylvacmus Ognev \& Vorobiev 1923 (Rodentia, Mammalia). Rad JAZU 383: 155-186.

TVRTković, N., Duulić, B. \& Mrakovčić, M. 1980: Distribution, species characters, and variability of the Southern water-shrew, Neomys anomalus Cabrera, 1907 (Insectivora, Mammalia) in Croatia. Biosistematika 6(2): 187-201.

ZÖRÉNYı, M. (1990): A bagolyköpetekből várható hazai emlősfajok határozókulcsa. Babits füzetek 1. Babits Mihály Mûvelődési Központ, Szekszárd.

YALDEN, D. W. 1977: The Identification of remains in Owl Pellets. An Occasional Publication of the Mammal Society No. 2. Reading.

Yalden, D. W. \& Morris, P. A. 1990: The Analysis of Owl Pellets. An Occasional Publication of the Mammal Society No. 13. London. 
Small mammal fauna of the region between Somogyszob, Hajmás and Kálmáncsa based on barn owl Tyto alba (Scopoli, 1769) pellet analysis

\section{JENÖ J. PURGER}

Barn owl pellets were collected in county Somogy (investigated area: XM72, XM82, XM81, XM92, XM91, YM02, YM01, YM00, YM12 and YM22 UTM grids) between 1993 and 2000, from 31 localities. In a total of 2429 barn owl pellets there were 8376 prey remnants (3.4 was the prey per pellet ratio). Small mammals were dominating (98.3\%). Remnants of birds, amphibians, diplopods and insects consisted $1.7 \%$ of total prey. Mammal prey consisted of Soricidae (Sorex araneus, Sorex minutus, Neomys anomalus, Neomys fodiens, Crocidura leucodon, Crocidura suaveolens) $47.85 \%$, Talpidae (Talpa europaea) $0.02 \%$, Vespertilionidae (Myotis myotis, Eptesicus serotinus, Plecotus austriacus) $0.05 \%$, Arvicolidae (Clethrionomys glareolus, Arvicola terrestris, Microtus agrestis, Microtus arvalis, Microtus subterraneus) $28.50 \%$, Muridae (Micromys minutus, Apodemus agrarius, Apodemus flavicollis, Apodemus sylvaticus, Rattus norvegicus, Mus musculus, Mus spicilegus and specimens belonging to genus Apodemus, Rattus and Mus) 23.25\%, Gliridae (Glis glis, Muscardinus avellanarius) $0.32 \%$, and Mustelidae (Mustela nivalis) $0.01 \%$.

Author's address:

Dr. Jenő J. PURGER

University of Pécs, Faculty of Sciences,

Institute of Biology, Department of Zootaxonomy and Synzoology

H-7624 Pécs

Ifjúság útja 6.

HUNGARY 